\title{
Premio Nacional de Historia, Ciencias Sociales y Filosofía 2002 a Adolfo Sánchez Vázquez
}

\author{
Elisabetta Di Castro
}

$\mathrm{E}$

ste año el Premio Nacional de Historia, Ciencias Sociales y Filosofía, que otorga el Gobierno Federal como uno de los principales reconocimientos a la trayectoria de destacados intelectuales del país, le fue conferido a Adolfo Sánchez Vázquez. Este premio se suma a una larga lista de reconocimientos que diversas instituciones nacionales y extranjeras le han hecho por su fecundo trabajo académico, entre los cuales podemos mencionar el emeritazgo como profesor de la Facultad de Filosofía y Letras de la UNAM, el Premio Universidad Nacional que otorga la misma institución, el emeritazgo como investigador del Sistema Nacional de Investigadores, así como los doctorados Honoris Causa recibidos por la Universidad Autónoma de Puebla, la Universidad de Cádiz, la Universidad Nacional de Educación a Distancia (de España), la Universidad Complutense de Madrid y la Universidad de Buenos Aires, además del de la propia UnAM.

Este importante premio nos da la ocasión de recordar una vez más la labor incansable que Sánchez Vázquez ha desarrollado en México desde su llegada como exiliado en 1939. Primero en Morelia y después en la ciudad de México, su preocupación por la política y la cultura ha sido una constante, siempre de acuerdo con un compromiso moral y teórico que trajo de España y perdura hasta la fecha: el marxismo. En este dominio, sus ideas se han ido afinando y depurando con el tiempo de acuerdo con un pensamiento riguroso que aboga por una sociedad más justa, más igualitaria y más libre; un marxismo vivo y antidogmático que gira fundamentalmente alrededor de tres aspectos básicos: el proyecto de transformación, la crítica de lo existente y el conocimiento.

Como profesor de múltiples generaciones de estudiantes y autor de más de veinticinco libros (algunos de ellos traducidos a diversos idiomas), Sánchez Vázquez ha reflexionado y hecho aportes en diversas áreas, como son la estética, la ética, la filosofía política, la filosofía de la historia y el pensamiento 
marxista. Entre sus principales contribuciones a este último destaca su Filosofía de la praxis, así como sus críticas al llamado "socialismo real" y la reivindicación de la idea misma de socialismo.

El merecido premio a Sánchez Vázquez llega en un buen momento, ya que se reconoce a una gran figura no sólo académica sino también moral de nuestro país. Sin duda la UNAM, y en especial el Colegio de Filosofía de la Facultad de Filosofía y Letras, se congratulan de la entrega de esta distinción a uno de sus más destacados profesores, cuyo trabajo a lo largo de décadas ha rebasado el ámbito universitario para enriquecer el bagaje cultural mexicano. 